\title{
Mathematical models and methods of optimization of technological heating regimes of the piecewise homogeneous glass shell. State-of-the-art investigations
}

\author{
Gachkevich M. G. ${ }^{1}$, Gachkevich O. R. ${ }^{1,2}$, Torskyy A. R. ${ }^{3}$, Dmytruk V. A. ${ }^{3,4}$ \\ ${ }^{1}$ Pidstryhach Institute for Applied Problems of Mechanics and Mathematics \\ National Academy of Sciences of Ukraine \\ 3-b, Naukova Str., 79060, Lviv, Ukraine \\ ${ }^{2}$ Opole University of Technology \\ 76 Pryszkowska str., 45-758 Opole, Poland \\ ${ }^{3}$ Centre of Mathematical Modelling IAPMM of Ukrainian National Academy of Sciences \\ 15 Dudayev str., 79005, Lviv, Ukraine \\ ${ }^{4}$ Lviv Polytechnic National University \\ 12 S. Bandera str., 79013, Lviv, Ukraine
}

(Received 1 July 2015)

\begin{abstract}
In this paper, the state-of-the-art investigations of optimization problems with respect to the stress state of technological heating regimes for piecewise-homogeneous glass shell elements have been analysed, which are important for development of different types of production processes during production of elements of modern devices for specific target application, in particular, vacuum and power equipment. The directions of development of this class of problems of optimization and corresponding approaches to their formulation and solving are identified.
\end{abstract}

Keywords: thermal regimes in manufacturing processes, glass piecewise homogeneous shell elements, optimization with respect to stress state

2000 MSC: 74A10, 74B 10

UDC: 539.3

\section{Introduction}

In many manufacturing processes, technological heating is commonly used, particularly in the manufacture of vacuum technology equipment. The main elements of this technique are usually glass elements of the shell type. Constructive and other diversities, especially under the conditions of gradient distribution of temperature, tend to significant stresses that can exceed the permissible values and lead to the breaking of such shell system [1-3, et al.]. Due to the low level of permissible stresses for glass (fragile material), the levels of stresses can exceed these permissible stresses and lead to the breaking such shells. Therefore, it s necessary to develop methods of constructing heating regimes being optimal with respect to the stress for glass piecewise homogeneous shells of rotation, which are widely used in engineering practice (as constituents of many devices).

During the manufacturing, treatment, and operation, the piecewise homogeneous glass shells or elements of these shells are exposed to unsteady temperature fields as a result of technological or concomitant heating and also to force loading. The levels of stresses and strains that occur significantly depend on both the heterogeneity of temperature distribution or the force load and the heterogeneity of material properties. Under overdimension of the permissible stresses, they can lead to arising cracks and breaking these shells.

Therefore, the problem of optimization with respect to the stress of regimes of heating such shells with taking into account their heterogeneity for the given domains of temperature permissible changes and thermal stresses that reflect the specific and performance capabilities of the particular method of 
technological or operational heating, as well as the durable properties of the material is very actual and urgent. Solving various aspects of this issue is important in constructing optimal thermal regimes of many types of target heat treatment of piecewise homogeneous shell elements (made of glass and other materials) - the constituents of a significant number of modern devices of target usage, including vacuum and power equipment, and therefore relating to the scientific trend of optimization in thermal mechanics.

\section{State of the problem}

In scientific direction, the optimization in thermomechanics is focused on the optimization of temperature fields and stresses in structural elements and devices (or within them in general) with integrated loads of different physical nature (force, thermal, electromagnetic, etc.), as well as optimization of factors of technological actions by the level of thermostressed state of elements under consideration.

Moreover we note that before, the needs of engineering were related to the development of structural optimization that is still urgent at present stage of industrial production, in particular, due to the extensive use of structures which operate under extreme loads of different nature. In this way, there are obtained a number of important theoretical and experimental results of general and applied nature [414, et al.].

Analytical investigations to determine the temperature fields which ensure the maximum low temperature of stresses to be occurred within the boundaries specified by conditions of local heating originate in 1967 from the work of Ye. Grigolyuk, Ya. Pidstryhach, Ya. Burak [15, et al.], the mathematical formulation and the solution of the problem to determine in the shells of rotation the local axially symmetric temperature fields constant with respect to the thickness under restrictions on quite general key functions are represented. The problems were solved on the basis of minimizing the energy functional of elastic deformation of the shell. When reducing the obtained nonclassical extreme problems to the problems of the calculus of variations, the mathematical tool of generalized functions was applied.

Further development of research in this field is obtained in Refs. [16,20, et al.]. They studied the optimal conditions for local heating isotropic inhomogeneous shells of rotation, flat orthotropic thin shells. The possibility of lowering the stress-strain state by power load and accompanied local heating was shown. As the criteria for optimality, along with the elastic displacement energy functional the forming energy functional was used and control functions were limited with domains of acceptable change.

The developed theoretical fundamentals and mathematical methods of optimization of the stressstrain state of thermoelastic shells and plates are generalized and systematized in the monograph [21], in which along with the stated above, the results are represented for investigations in optimal control under heat transfer and induction heating, optimization of local heat treatment of the welded thinwalled structures, the influence of temperature dependence of the characteristics of the material on optimal conditions of local heating.

Methods of optimal control of heating spherical shell at heat transfer outlined in [21], was developed for the class of thin shells of different geometry with constraints that are characteristic of existing in engineering methods of heating. Here the initial stage is minimization of the elastic displacement energy functional over the time of heating. The temperature field and the stress state are assumed to be non-stationary (quasi-static formulation of direct thermomechanics problems) and the regimes of heating are to be optimized. Some summarized results in this area of research, as well as solutions of the relevant extreme problems of thermoelasticity arising during optimization of thermal regimes of production and processing of certain elements of electric vacuum devices are contained in the book [22].

To the development of theoretical fundamentals of optimization of heating regimes for thin glass shells variable in time and by the coordinates at specified domains of permissible changes of temperature field and stresses are devoted Refs. [23-36, et al.]. In these works, there are suggested optimization 
techniques in which the initial mathematical models are more adequate to the processes and phenomena under consideration (three-dimentional accounting for the vitrification process, etc.), as well as systems of restrictions, control functions, and criteria of optimality.

Further development of mathematical models of calculation and optimization of heating regimes for metal and glass plates and shells, in particular the thermal heating with radiation, heating with material phase transformations, including cases of shape memory effect, is suggested in [37].

To the construction and study of optimal transients regimes of loading thermoelastic shells in order to reduce the impact of the dynamic effects on their stress state while reducing the level of stress are dedicated Refs. [19, et al.].

Ya. Pidstryhach and V. Vihak (in 1972-1973) suggested the method of inverse problem of heat conduction and thermoelasticity for solving the optimal control (with respect to performance) of nonstationary temperature regimes in strain solids with constraints on the control, quasistatic temperature stresses and settings of thermal regime (under control, which is realised under the conditions described by the system of given constraints). The method was substantiated and developed, and applied to solving problems of optimization of thermoelastic stresses and displacements control in the body due to internal heat sources in Refs. [38-40, et al.]. Results on the present state of this research, including generalizations of the elastic-plastic formulation, are systematized in [40].

In Refs. [41,42, et al.], the computational schemes and effective analytical methods for determining and optimizing thermostressed state of conductive bodies, including plates and shells, under the influence of harmonic electromagnetic field are developed. Optimal by stresses regimes for induction heating plate elements are constructed.

To the said above areas of research, close by their scientific nature researches conducted under the guidance of Yu. Nyashin can be referred [43,44, et al.], by their model construction and optimization techniques for initial stresses and strains, which account for thermo-elastic and plastic nature of the character of deformation. Here are developed general principles of stress control through initial stresses in the bodies of different materials, as well as there are suggested approaches to the generalizing of control theory to living tissues.

Along with sufficiently developed methodology for optimizing by the stress state of physical and mechanical processes in homogeneous plates and shells, there are only a few studies dedicated to the development of the considered above issues for piecewise homogeneous shells $[17,60$, et al.]. These studies are fragmented and require generalization and systematization.

\section{Piecewise homogeneous shells}

Homogeneous and piecewise-homogeneous elements of different structures and devices of modern technology, including glass ones, are exposed to multifactor loads. One of them is the thermal load, the effect of which is the basis of the various energy devices operating and it also is used in existing technologies of the treatment of structural elements in many industries, including energy, electrical and electronic.

The main source of heat action is convection way of heating. There are used often the method of heating with the help of heat sources, in particular caused by infrared electromagnetic radiation. Structural elements can be subjected to the direct force load as a result of appropriate fixation and additional force action. Items can be subjected to such acts both during the manufacturing and during exploitation.

Heating and force load in constructive elements give rise to temperature and mechanical (stress and strain) fields that depend both on the nature of the distribution of temperature and force load and the nonhomogeneity of material, and they can reach considerable values and exceed allowable levels, lead to cracks and destruction of these elements.

It is mentioned above, that the development of theoretical research in optimizing the mechanics of deformable solids can be divided into two directions: optimization of structural design and optimization 
of control of physical and mechanical fields in structural elements, in particular their stress-strain state in the manufacturing, treatment, and exploitation.

The need to reduce the material consumption of structures and to improve their mechanical properties, and to create new technology products, in recent decades led to the intensive development of the first direction. The theory of optimization of stress-strain state control of structural elements in their manufacturing, treatment, and use, as compared to the first direction is less developed. There are a number of studies on this subject for homogeneous shells and bodies with canonical geometry, which are produced on the basis of methods of optimal control. There are only a few known results related to the optimization of the stress state of piecewise homogeneous shells obtained by constructing the respective local stationary temperature field of annealing for piecewise homogeneous cylindrical and spherical shells. However, the suggested there method of optimization of the stress-strain state does not allow us to construct by the stress state the optimal heating regime of piecewise homogeneous shells for a given range of allowable values of temperature and stresses.

Therefore, the development of a methodology for determining optimal by stresses statre heating regimes for piecewise homogeneous glass shells with taking into account their heterogeneity for a given range of allowable temperature and stresses changes that reflect the specifics and possibilities of a specific way of technological or operational heating as well as durable (thermal and strength) characteristics of the material. A solution of this class of problems is essential for the development of thermal regimes of different types of target treating piecewise homogeneous glass shells, which are widely used in various fields of modern technology [24,26, et al.].

Formulation and solving the optimization problems in mechanical systems with distributed parameters, which include the general problems, are connected with solving of the following key tasks:

- choise of a system of defining functions that include functions and parameters of control;

- formulation of a corresponding analytical model of optimization;

- development of basic mathematical models describing thermomechanical behavior of systems under consideration and optimality criteria;

- forming restrictions on temperature, stress and strain in the proposed glass design;

- development of analytical or numerical-analytical methods for solving the existing direct and inverse component problems;

- correction of regime parameters of heat treatment depending on the size of the construction and on the way of treating in the particular technology.

Since most of the technological processes take place in conditions of intense heat load, which occurs in a wide temperature interval, we must take into account the temperature dependence of physical and mechanical characteristics of the material. As it is known, the values of coefficients of linear thermal expansion for different types of technical glass (used in the production) with temperature being increasing, significantly change [1-3,46,47 et al.], and coefficients of temperature conductivity, Poisson and Young's modulus within limits of considered temperatures $\left(0^{\circ} \mathrm{C}-460^{\circ} \mathrm{C}\right)$ change insignificantly and they can be taken as constants. Therefore, for describing the stress-strain state of the considered piecewise homogeneous glass shells, it is expedient to begin to proceed with relations unbound thermoelasticity problem with temperature-dependent thermal expansion coefficient, which is often used in the study of thermomechanical behavior of specific glass elements caused by non-stationary thermal-force load.

In the formulation of problems of stress-stain state optimization, it is of great important the choise of optimality criterion. For homogeneous shells, as a rule, the appropriate functionality is chosen, which in integral sense reflects the objectives of optimization. In particular, the functionality of elastic strain energy used in the construction of optimal technological regimes of heating homogeneous shells is related to the heat resistance of glassware at heating-cooling stages $[21,22$, et al.]. Piecewise homogeneous shells have the peculiarity that thermal stresses that occur during heat treatment, can greatly depend not only on the nature of the distribution of temperature, but also on the heterogeneity of the material properties. And, as a rule [2,47 et al.], the maximal normal stresses (the magnitude of 
which according to the first theory of strength can break glass) arise in the near contact (local) field of coupling heterogeneous parts of piecewise homogeneous shell. Therefore, in the case of optimizing the stress-strain state of piecewise homogeneous shell it is expedient to use a local criterion of optimality that characterizes the stress state. As such optimality criterion, the maximal normal stresses functionality can be chosen.

In this approach, the initial complex nonlinear optimization problem can be greatly simplified by the assumption about the behaviour of the temperature distribution with respect to the thickness of the shell. As such assumption, quite often the cubic law of temperature distribution in the thickness of each composite element of the shell can be taken, thus with sufficient accuracy the nature of temperature changes in the thickness coordinate is described [21 et al.]. This is still a nonlinear optimization problem and it can be solved only using numerical methods of optimization theory. As a method for solving the formulated optimization problems, the method of local variations (phased parametric optimization) can be chosen, moreover, for implementation of the search of constrained minimum of the mentioned above functionality the direct search methods are applied [49-52 et al.] at a known solution of the direct problem.

\section{Optimization of physical and mechanical processes}

In this passage, with taking into account the research results represented in monographs and review articles $[7,16,19,21,38-40,45,47,48$, et al.], some approaches to building optimization models of constructions and physical and mechanical processes in thermomechanical systems that can be used in the development of methods for optimizing by the stress state of target regimes of heating piecewise homogeneous glass shells.

As noted above, it happened historically that the development of research in the optimization in the mechanics of deformable solids can be divided into two directions: control and optimization of physical and mechanical processes in structural elements in their manufacturing and exploitation.

The need to reduce material consumption of constructions and to improve their mechanical characteristics led to the rapid development in recent decades both the optimal control theory and numerical methods for solving extreme problems [50,52, et al.]. This led to the intensive development of structural design optimization as evidenced by numerous articles and monographs on issues that are related to this direction $[4,7-11,52$, et al.].

Structural optimization problems in most cases can be reduced to problems of optimal control in systems with distributed parameters. The fundamentals of theory and methods of optimal control in such systems are set out in Refs. [52,54, et al.].

There are a number of approaches and numerical algorithms for solving various problems of optimal control in systems with distributed parameters. First of all, here we should mention direct methods $[49,51,52,57$ et al.]. Solving a number of problems is connected with indirect methods, in which using the principle of maximum by A. Pontryagin, the initial variational problem is reduced to the boundary value problem [48,51,52,58 et al.]. The solving methods based on nonlinear programming for variational problems have made great progress [51,52,59 et al.]. In Refs. [51,52, et al.], the approach based on variations of the control function state in space at a known solution of direct problems was suggested.

The results of studies on the development and application the numerical and analytical methods to solving direct problems of mechanics of thin-shelled structural elements are contained in Refs. [21,38,39,53, et al.].

The theory of control optimization of physical and mechanical processes in structural elements is processed in literature much less (compared to the previous direction). Here, works on control of thermostressed displacements in important applied problems of production are distinguished $[16,17,18,23,27,45,54$ et al. $]$.

To the first researches in this area it should be referred the works on building local temperature fields of annealing of welded thin-walled structures [16,18,21, et al.]. Here the boundaries set restrictions on 
the distribution of temperature and stresses under heating ensure optimal conditions for relaxation of residual stresses. It should also emphasize the Refs. [15,21, et al.], in which the optimal temperature fields near the circular welded joint zone are determined under the assumption that the temperature outside this zone is set, and for cylindrical shell under local heating vicinity of helical welded joint.

In Refs. [15,21,27 et al.] the theoretical fundamentals of optimal thermal heating conditions for homogeneous thin-walled shells were developed. Using methods of calculus of variations, on the basis of various criteria of optimality, the solution of a number of certain optimization problems for shells of rotation under the assumption of linear and the cubic law of change of temperature with the thickness coordinate were obtained. Based on this theory, a number of methods to determine the optimal target heating temperature fields have been suggested [17,20,23,27,28,42,45, et al.]. These techniques are developed for a broad class of optimization problems for stress state of thermoelastic shells, both thermal and force loads being controlled. A more complete review of the literature in this area is presented in Refs. [14,16,21,22, et al.]. Note that if to compare the results of the above studies, only in Refs. $[17,45]$ the local temperature fields in piecewise-homogeneous cylindrical and spherical shells are considered. In Refs. [26,55,56, et al.] a numerical method of heat treatment process optimization of piecewise homogeneous solids of rotation under constraints on the stress state. Here, to describe the thermomechanical behavior of such solids, there are used the model of thermosensitive elastic body in three-dimensional formulation under condition of the dependence of the characteristics of the material on the spatial coordinate. However, these proposed optimization methods do not allow us to build the piecewise homogeneous shells heating regimes to be optimal by stresses for the specified rages of allowable temperature and stress changes.

For determining the optimal temperature fields at local heating of thin shells, we did not impose any restrictions on a law of changes with respect to the coordinates and time, ambient temperature, heating rate, etc. At the same time, based on optimal temperature fields of engineering applications, it must be taken into account restrictions associated with specific features and capabilities of a particular method of heating. Such restrictions at heating the shell by means of convective heat exchange with the environment can correspond to, for example, the setting the limits of allowable changes of ambient temperature, temperature on the surface of the shell, etc.

These researches on optimization of the stress-strain state of structural elements and products were based mainly on optimality criteria - the minimum of elastic strain energy $[15,21,27,28$, et al.]. It was assumed a heating scheme to be given, a regime of heat treatment being required.

The optimal regimes of heating of thin shells of rotation in conditions of heat transfer from the lateral surfaces at the specific permissible changes of temperature field and temperature stress. The investigations were carried out for homogeneous shells without accounting the temperature dependence of material characteristics assuming cubic law of temperature change in the thickness of the shell. Built using such techniques regimes of thermovacuum treatment of glass shells of specific electron-beam devices are widely used in electrovacuum manufacturing [21,22, et al.].

To the development of this technique (the determining optimal stress regimes) with induction heating in plates and shells, the works $[21,42]$ are devoted, in which the heating control is carried out by internal heat sources created by electromagnetic means. To the construction of theoretical fundamentals and methods of optimization of dynamic stress state of thin shells when the control functions are external force load and heat sources, there are dedicated Refs. [19,20, et al.].

Approaches to identify and study the optimal by thermal processes control speed in thermoelastic and thermoviscoelastic bodies by their reduction to the corresponding correct or incorrect inverse heat conduction problems (with constraints on the control parameters, parameters of heat treatment and stress-strain state) are suggested in Refs. [38-40, et al.]. Here it is also formulated sufficient conditions for optimality and proved the existence of the solution. However, such approaches do not allow us to implement optimality criteria, as well as to provide a satisfaction of certain restrictions.

The performed analysis of the literature shows that the issues of optimization by the stress state of the piecewise homogeneous shells heating regimes are still not enough studied. 
In Ref. [21], there are formulated the theoretical bases of optimal thermal heating regimes constructions for homogeneous shells during their annealing process. Using methods of calculus of variations at different optimality criteria, a method of solving a number of specific optimization problems for shells of rotation under the assumption of linear and cubic law of temperature change in the thickness of the shell is suggested. This method is developed and extended to a wide class of problems of optimization by the stress state of thermoelastic shells of the thermal regimes of aging for different ways of heating and force load. But only a few studies [17,60, et al.] were dedicated to determining local temperature fields of aging in piecewise homogeneous cylindrical and spherical shells. However, the suggested in these studies approaches to optimize the stress-strain states do not allow building the optimal by stresses regimes of heating piecewise homogeneous shells, particularly under the specified allowable temperature and stress change ranges that always occur in real regimes of a certain product heating.

In publications relevant to this direction, for piecewise homogeneous shells in recent years $[29,31,32,55]$, the mathematical formulation has been done as well as a method for solving optimization problems by heating regime stress state has been suggested for thin glass composite shells of rotation (including their heterogeneity). Heating the shell (of the thickness $2 h$ consisting of $n$ heterogeneous units, referred to the mixed orthogonal coordinate system $\alpha_{1}, \alpha_{2}, \gamma$, in which the coordinates of the curve are curves of the main curvatures, and the coordinate $\gamma$ determines the position of a point along the normal to the middle surface $(-h \leqslant \gamma \leqslant h)$ ) is performed due to convective heat exchange with the environment, the temperature of which $f=\left\{t_{1(k)}^{c}, t_{2(k)}^{c}\right\}$ is a control function (heating factor). The conditions of heat exchange on the shell surface have the form:

$$
\begin{aligned}
& \frac{\partial t_{(k)}}{\partial \gamma}+h_{t_{(k)}}^{(1)}\left(t_{(k)}-t_{1(k)}^{c}\right)=0, \quad \gamma=h, \\
& \frac{\partial t_{(k)}}{\partial \gamma}-h_{t_{(k)}}^{(2)}\left(t_{(k)}-t_{2(k)}^{c}\right)=0, \quad \gamma=-h,
\end{aligned}
$$

where $t_{(k)}$ is the temperature of the shell, $h_{t_{(k)}}^{(1)}, h_{t_{(k)}}^{(2)}$ are the relative rates of heat transfer from the surfaces $\gamma= \pm h ; t_{1(k)}^{c}, t_{2(k)}^{c}$ are the ambient temperatures on these surfaces; $k=\overline{1, n}$ is the index introduced to denote quantities belonging to regions of homogeneity.

In addition to these boundary conditions for convective heat transfer, the closed shell can be in more difficult conditions of heat exchange with the internal medium, which can be expressed by means of functional correlations, namely

$$
t_{2(k)}^{c}=F\left(t_{(k)}, h_{t_{(k)}}^{(2)}, \lambda_{(k)}, \ldots\right)
$$

which links the temperature of the medium with the temperature and geometry of the shell as well as with the thermal properties of the material and the medium.

The temperature field inside the shell region is described by known heat conduction equation

$$
p_{(k)}^{2} t_{(k)}+\frac{\partial^{2} t_{(k)}}{\partial \gamma^{2}}=0
$$

where $t_{(k)}$ is temperature, which is measured from the initial $t_{0}$;

$$
p_{(k)}^{2}=\Delta-\frac{1}{a_{(k)}} \frac{\partial}{\partial \tau} ; \quad \Delta=\frac{1}{A_{1} A_{2}}\left[\frac{\partial}{\partial \alpha_{1}}\left(\frac{A_{2}}{A_{1}} \frac{\partial}{\partial \alpha_{1}}\right)+\frac{\partial}{\partial \alpha_{2}}\left(\frac{A_{1}}{A_{2}} \frac{\partial}{\partial \alpha_{2}}\right)\right],
$$


$a_{(k)}=\frac{\lambda_{(k)}}{c_{(k)} \rho_{(k)}}$ is the temperature conductivity coefficient; $\lambda_{(k)}$ is the thermal conductivity coefficient; $c_{(k)}$ is the specific heat capacities; $\rho_{(k)}$ are the densities; $A_{1}, A_{2}$ are the coefficients of the first quadratic forms of middle surface.

The regions of allowable temperature changes and temperature stresses reflecting the specificity and possibilities of a certain method of heating, as well as describing the durable properties of the material are given. It is assumed, in particular, that restrictions on the temperature and temperature stresses are given by means of the following inequalities:

$$
\begin{gathered}
t_{0 l}^{ \pm} \leqslant t_{(k)}^{ \pm} \leqslant t_{* l}^{ \pm}, \quad t_{01}^{c} \leqslant t_{1(k)}^{c} \leqslant t_{* 1}^{c}, \\
t_{02}^{c} \leqslant t_{2(k)}^{A} \leqslant t_{* 2}^{A}, \quad V_{T 1} \leqslant d t_{(k)}^{ \pm} / d \tau \leqslant V_{T 2}, \\
\sigma_{011}^{(k) \pm} \leqslant \sigma_{11}^{(k) \pm} \leqslant \sigma_{* 11}^{(k) \pm}, \quad \sigma_{022}^{(k) \pm} \leqslant \sigma_{22}^{(k) \pm} \leqslant \sigma_{* 22}^{(k) \pm},
\end{gathered}
$$

where $\sigma_{011}^{(k) \pm} \leqslant 0, \sigma_{022}^{(k) \pm} \leqslant 0, \sigma_{* 11}^{(k) \pm} \geqslant 0, \sigma_{* 22}^{(k) \pm} \geqslant 0, V_{T 1}, V_{T 2}$ are the given allowable heating rates; $t_{0 l}^{ \pm}, t_{* l}^{ \pm}, t_{01}^{c}, t_{* 1}^{c}, t_{02}^{c}, t_{* 2}^{c}, \sigma_{011}^{(k) \pm}, \sigma_{* 11}^{(k) \pm}, \sigma_{022}^{(k) \pm}, \sigma_{* 22}^{(k) \pm}$ are the given values of allowable temperatures and stresses.

Hereinafter, the signs "+", "-" are used to denote the functions and variables on the outer and inner surfaces of the shell respectively.

Problems are solved in quasi-static formulation and assuming that distribution of the temperature with the thickness' coordinates is described by the third degree polynomial (cubic distribution law), and the coefficients of thermal expansion depend on the temperature. As the optimality criterion, the minimum of the maximal normal stresses functional is chosen.

$$
\begin{gathered}
N=\max \left\{\sigma_{11}^{(k)}\left(\alpha_{1}, \alpha_{2}, \gamma, \tau\right), \sigma_{22}^{(k)}\left(\alpha_{1}, \alpha_{2}, \gamma, \tau\right)\right\}, \\
\alpha_{1}, \alpha_{2}, \gamma \in\left(V_{0}\right) ; \quad k=\overline{1, n}, \quad 0 \leqslant \tau \leqslant \tau_{*},
\end{gathered}
$$

where $\tau_{*}$ is the duration of the heat treatment regime, $V_{0}$ is the range of coordinate changes in threedimensional Euclidean space, which a piecewise homogeneous shell occupies. The control function is the temperature of the heating medium. Problems are solved by numerical method of local variations (successive approximation) based on variations in state space of the control function at a known solution of the direct problem. It is also suggested an algorithm for constructing the control function initial approximation.

The analytical model of the direct problem of the corresponding structural part of the optimization problem by the stress state is developed for technological heating regimes of the thin glass piecewise homogeneous shells of rotation, which is reduced to determining the temperature field in the corresponding heat conduction problem (1)-(3) for piecewise homogeneous shell and further obtaining the parameters of the stress-strain state based on the thermoelastic thin shells correlations for thermosensitive coefficient of linear expansion of the material. Moreover, besides the representation of the temperature distribution with the thickness coordinate as a third degree polynomial, the methods of net-points and least squares at finite-element approximation of the average temperature and the temperature moment are used. The correlations of thermomechanics of piecewise homogeneous shells of classical geometry (with components of cylindrical, spherical or conical profile) are reduced to the key equations whose solution is obtained in analytical form.

For such shells, the method of constructing the initial approximation of the control function, in which the reference condition is the optimal thermal regime for homogeneous spherical shell, when as an optimality criterion is chosen the appropriate functional of shell elastic deformation energy over the time of heating, is suggested. Based on the proposed method, a number of optimization problems by the stress state of heating regimes for glass piecewise homogeneous shells of classical geometry are 
solved, in particular, in the presence of heat and force load, thermal sensitivity of allowable stresses some technologies of manufacturing and treatment of elements of glass products are studied.

The change in time of the optimal temperature for piecewise homogeneous cylindrical shell (consisting of three heterogeneous parts) calculated using the above-described methods taking the values of permissible tensile stresses on the inner and outer surfaces equal to $9 \mathrm{MPa}$ and $7 \mathrm{MPa}$ respectively is illustrated in Fig. 1. The solid curves show the change in time of the optimal temperature $t^{+}(\tau)$ and temperature stresses $\sigma$ on the outer and inner surfaces of the shell. When heating from the initial temperature to the maximum temperature, tensile stresses occur on the inner surface of the shell and when cooling - on the outside. Thus, on the inner surface the stresses to be calculated are circular ones, and on the outer surface - the meridional ones. In Fig. 1, the dotted-dashed curves illustrate the change in optimal surface temperature for homogeneous cylindrical shell made of a material of the third part of piecewise homogeneous shell. The temperature is determined on the basis of minimizing the elastic deformation energy functional. Dashed curves show the refined on the basis of local variations optimal heating regime while the maximal normal stresses functionality being minimized (for the same in all cases the permissible temperature tensile stresses of $7 \mathrm{Mpa}$ and $9 \mathrm{MPa}$ respectively).

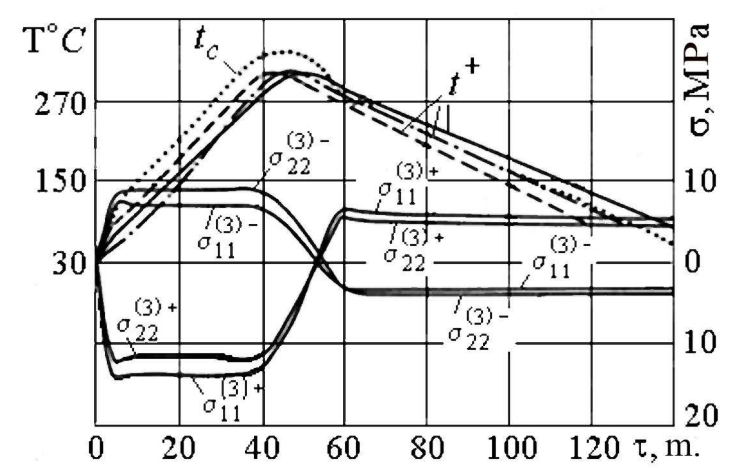

Fig. 1.

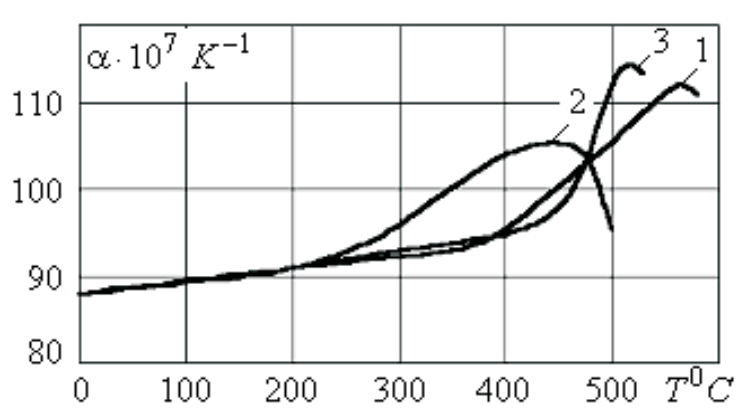

Fig. 2.

It is seen that taking into account the shell heterogeneity increases the duration of the regime.

The dependence of the coefficients of linear thermal expansion on the temperature for the structural parts $1-3$ of the shell is shown in Fig. 2.

The problem having been considered here is a logical development of the research on criteria optimization of the stressed state in the thermomechanical systems under external loads, the results of which are represented in the monographs [19, 21, 22, 42]. Partially these results are obtained because of scientific cooperation of the Pidstryhach Institute for Applied Problems of Mechanics and Mathematics of NAS of Ukraine and its Center for Mathematical Modeling, G. S. Pisarenko Institute for Problems of Strength of NAS of Ukraine, Lviv Polytechnic National University, Ivan Franko National University of Lviv, Opole Polytechnic, and manufacturing enterprises interested in using the results of such research.

In our opinion, an important for modern applications of optimal regimes of heating glass piecewise homogeneous shells are the following directions for further investigations in this area:

- processing of methods of optimization of technological heating regimes for piecewise elements made of glass and various metals as structural components, which are shell elements of not only classical geometry type;

- development and synthesis of mathematical models describing the thermostressed state for piecewise homogeneous shells (thermomechanics direct problems formulation), in particular, taking into account the real distribution of temperature, contact effects in the vicinity of the conjugations intersection at significant difference of characteristics of the material of structural components, thermomechanical behavior of glass materials at elevated temperatures (processes of viscosity, vitrification, relaxation, structural changes and temperature dependence of all characteristics of the material), etc.; 
- constructing shell optimal heating regimes taking into account the possibility of local loss of stability due to the presence of significant compressive stresses;

- development of more efficient exact and approximate optimization algorithms based on modern theories and methods of optimal control, in particular, related to the use as a control function the heat and power loads, and other criteria of optimality and methods of optimal search;

- development of theory and methods for solving nonclassical direct and extreme problems of mathematical physics, which are formulated within the framework of the proposed models and algorithms;

- development of methods of experimental studies of physical and mechanical processes in shells in terms of the existing heating regimes (with target verification of assumptions adopted in the suggested regimes).

As for an initial formulation of the optimization problem and corresponding direct problems, the main constraints on the parameters of the problem, optimality criterion, and optimal solution methods (method of local variations) for this class of problems, it is enough to take the assumptions given above, which are processed and substantiated in literature for piecewise homogeneous shells of classical geometry.

\section{Conclusions}

1. In the literature, virtually there is no methods of optimization with respect to different target criteria of heating regimes (thermal regimes) of piecewise homogeneous shells, in particular made of glass, with respect to the stress state. Such shells or their elements are often used in engineering practice, for their production technological heating being widely used. They can also be exploited in different thermal regimes. For solving actual problems related to engineering and technological applications of such shells or their elements, it is important to develop a methodology to optimize with respect to the level of the stress state of heat regimes satisfying the constraints of various kinds (functional, durable, material science, technology, energy, etc.).

2. It has been established that for homogeneous shells all existing methods of target optimization of heating regimes are based on relatively simple laws (linear and cubic) distribution of values with the thickness with an optimality criteria - the elastic strain energy functional of the shell over the time of heating (which is an integral measure of the stress state in shell with respect to the coordinates and in time). Assumed laws of the thickness value distribution allows us to use as much as possible the analytical transformations and under the relative simplicity of these laws we can reduce complicated (complex) optimization problems to numerical analysis capabilities with sufficient accuracy of results.

3. The suggested in the literature methods of target optimization of thermal regimes of homogeneous shells and shell elements do not allow us to take into account the peculiarities of thermal and mechanical processes in the vicinity of conjugations intersections of heterogeneous parts, to construct optimality criteria with regard to heterogeneities, and to develop optimal with respect to the stress level heating regimes for piecewise homogeneous shells under specific ranges of allowable temperature changes and stresses, and under certain restrictions of technological nature.

4. In the literature, there is suggested a physico-mathematical model and the problem formulation of determining optimal with respect to the stress state regimes of heating with respect to external medium and heat sources of piecewise homogeneous shells of rotation, the constituent elements of which are shells of classical geometry: cylindrical, spherical, and tapered, in presence of force load and for specified ranges of acceptable values of temperature and stress changes. Optimization is performed by selecting ambient temperature, which is a function of control. It is assumed that the temperature with the shell thickness varies according to the cubic law and an optimality condition is the minimum of maximal normal stresses functional. To describe the thermostressed state, the correlations of unrelated theory of thin shells thermoelasticity depending on the temperature coefficient of thermal expansion of the material (which are reduced to the key equations) are chosen.

Mathematical Modeling and Computing, Vol. 2, No. 2, pp. 140-153 (2015) 
A solution of the formulated problem is constructed on the basis of the principle of gradual parametric optimization, using at the stage of the conditional minimum search of the method of local variations, which is based on variations in state space of the control function at a known solution of the direct problem. Thus for determining the initial approximation of the control function, it is proposed an iterative algorithm based on the solution of the problem of optimizing the heating regime for homogeneous spherical shell under the given constraints on temperature and stress. There are constructed and analyzed the optimal conditions for specific piecewise homogeneous shells under different conditions of heat transfer and peculiarities of technological processes.

This approach to formulation and solving the problem of heating regimes optimization for piecewise homogeneous shells under restrictions on the stress state reflects the formulated conditions of optimization and can be applied to the development of formulation and methods of solving this class of problems with taking into account: the objectives of optimization, optimality criteria, restrictions on the parameters of processes and control, models describing thermomechanics of shells, etc.

[1] Bartenev G. M. Mechanical properties and heat treatment of glass. Moscow, Stroyizdat (1960).

[2] Rowse B. Glass in electronics. Moscow, Sov. radio (1969).

[3] Espe B. Technology of electrovacuum devices. Moscow, Energia. 2. (1968).

[4] Banichuk N. V. Introduction into optimization of construction. Moscow, Nauka (1986).

[5] Dzyuba A. P., Vasilenko O. G., Dzyuba O. A. About one approach for solution of optimizational problems structural elements considering joint action power loads and aggressive environments. Methods of solving applied problems of mechanics of deformable solid. 8, 55-66 (2007).

[6] Krysko V.A., Pavlov V.A. Shape optimization of thermoelastic solids. Saratov, Sarat. state. University Press (2000).

[7] Majid K.I. Optimal design of structures. Moscow, Higher school (1979).

[8] Nemirovsky Y.V., Mishchenko A.V., Vokhmyanin I.T. Rational and optimal design of layered bar systems. Novosibirsk NGASU (2004).

[9] Savula Y.G., Fleishman N.P., Shcherbaty M.V. Shape optimization of elastic shells of rotetion. Math. methods and physical and mechanical filds. 19. 74-78 (1984).

[10] Sarkisyan V.S., Geghamyan B.N. Some problems of optimal design of anisotropic and inhomogeneous plates and shells. Problems of optimization in engineering. Kharkiv. P.82 (1982).

[11] Troitsky V.A., Petukhov L.V. Shape optimization of elastic bodies. Moscow, Nauka (1982).

[12] Drobenko B.D. Optimal design of T-joints. Physic.-Chemical Mechanics of Materials. 6, 89 (1984).

[13] Mangeron D., Poterasu V. F., Vulpe A. Teoria optimizacii structurilor cu aplicatii. Iasi: Junimea, 1980.

[14] Kruzelecki J. A review of optimal structural design of shells. 3rd Conference thinwalled vessels-Karlow 2004. 39 p.

[15] Grigolyuk E.I., Burak Y.I., Podstrihach Ya.S. On an extremal problem of thermoelasticity for an infinite cylindrical shell. Report of Academy of Sciences of USSR. 174, n.3, 534-537 (1967).

[16] Besedina L.P., Budz S.F., Zozulyak Y.D. On the construction of optimal thermal stress fields applying to the conditions of the heat treatment of plates and shells. Mat. Methods and Physics and Mechanics Fields. 7, 11-16 (1978).

[17] Besedina L.P., Burak Y.I., Podstrigach Ya.S. On the optimal heating of irregular shells of rotation. Mechanics of Solids. 6, 110-116 (1973).

[18] Burak Y.I., Zozulyak Y.D. Extreme temperature field and the stresses at local heating of a spherical shell. Applied mechanics. 6, n.12, 74-81 (1970).

[19] Burak Y.I., Zozulyak Y.D., Hera B.V. Optimization of transient processes in thermoelastic shells. Kiev, Naukova Dumka (1984).

[20] Zozulyak Y.D., Damanskii P.P. Application of extreme changes in temperature and force load to improve the efficiency of local heat treatment of shells of rotation. Mat. Methods and Physics and Mechanics Fields. 7, 111-115 (1978). 
[21] Grigolyuk E.I., Podstrigach Ya.S., Burak Y.I. Optimization of heating shells and plates. Kiev, Naukova Dumka (1979).

[22] Podstrigach Ya.S., Burak Y.I., Shelepets V.I. et al. Optimization and control in electrical vacuum production. Kiev, Naukova Dumka (1980).

[23] Budz S.F. Optimal with respect to thermal stresses thermal regimes of zone annealing cylindrical shell. Phys. Chemical Mechanics of Materials. 4, 116-118 (1974).

[24] Budz S.F., Gachkevich N.G. Optimizing heat treatment of piecewise homogeneous shells EBL considering temperature dependence of the characteristics of the material, Phys. Chemical Mechanics of Materials. 5, 111-113 (1987).

[25] Budz S.F., Gachkevich N.G., Rodichev Y.M., Zolotarev P.F., Yakubishin A.T. Optimization of thermal treatment for the formation of compounds on the basis of glass-ceramic sealant in glass shells, Problems of strength. 2, 52-58 (1993).

[26] Budz S., Irza Ye., Kaspersky Z. Optimal by control speed cooling of glass solids of rotation under constraints on residual stresses. Visnyk of Donetsk university. Ser. A, Natural Sciences. 1, 59-62 (2008).

[27] Burak Y.I., Budz S.F. Determination of optimal modes of heating a thin spherical shell. Applied Mechanics. 10, n.2, 14-20 (1974).

[28] Burak Y.I., Budz S.F., Irza E.M. Optimization of heating a spherical shell with a heat transfer coefficient variable with time. Mat. Methods and Physics Mech. Fields. 8, 58-60 (1978).

[29] Gachkevich O.R., Gachkevich M.G., Sosnovyy Yu.R., Terletskyi R.F. Optimization of heat treatment of electrovacuum devices using electromagnetic radiation. Proceedings of Ukrainian Vacuum Society. 1, Kiev, P.317-319 (1995).

[30] Gachkevich A.R., Gachkevich N.G. Optimal heating by environment of piecewise uniform shells of rotation with internal heat sources. Journal of Applied Mechanics. 31, n.11, 51-57 (1995).

[31] Gachkevich A., Gachkevich N., Ghazaryan K., Kaspersky Z. Optimal technological heating by environment and heat sources of glass piecewise homogeneous cylindrical sell conjugated with a conical one. Proceedings of the National Academy of Sciences, Armenian Mechanics. 55, n.1, 40-54 (2002).

[32] Gachkevich M., Kaspersky Z., Trisch B.M., Chornyy B.I. Problems of thermoelasticity of piecewise homogeneous shell rotation at optimization of heating and force load. Visnyk of Donetsk university Ser. A. Natural Sciences. 2, 80-84 (2002).

[33] Gachkevich A., Gachkevich N., Irza E., Kaspersky Z. Simulation of processes of local heat treatment at optimization of the conjugating of glass bodies. Proektowanie i automatyzacja procesow produkcyjnych. Ksiazka pod red. A. Swic. - Lublin: W-wa Uczelniane Politechniki Lubelskiej. 2005. P.115-121 (172 p.).

[34] Gachkevich A.R., Gachkevich M.G., Shimura S.R. Optimal thermal modes of glass-ceramic sealant joint of shell structures with regards of thermosensitivity of allowable stresses. Visnyk of Donetsk university Series A. Natural Sciences. 1, 150-156 (2008).

[35] Gachkevich A.R., Gachkevich N.G., Irza E.M., Trisch B.M. Mathematical model of optimization of lowtemperature heating piecewise homogeneous solids of rotation. Theoretical and Applied Mechanics. 43, 35-39 (2008).

[36] Gachkevich A., Gachkevich N., Irza E., Kaspersky Z., Trisch B. Method of numerical optimization of annealing glass bodies of rotation. Mashynoznavstvo. 4(142), 26-28 (2009).

[37] Lokhov V.A., Nyashyn Yu.I., Kuchumov A.G., Gachkevich A.R., Onyshko A.E. Stress control in living systems using the shape memory effect. Visnyk of Perm State Technical University. Applied Mathematics and Mechanics. 34-40 (2008).

[38] Vihak V.M. Optimal control of non-stationary temperature conditions. Kiyev, Nauk. Dumka (1979).

[39] Vihak V.M. Control of thermal tension and movement. Kiyev, Nauk. dumka (1988).

[40] Modeling and optimization in thermomechanics of electroconductive heterogeneous bodies / Ya. J.Burak, R. M. Kushnir. V.5. Optimization and identification in termomehanics of heterogeneous bodies / R. M. Kushnir, V. S. Popovych, A. V. Yasinskyy. Lviv, SPOLOM (2011).

[41] Burak Ya.I., Gachkevich A.R. Optimal by tension regimes of induction heating of a thin plate. Math. methods and phys.-mech. fields. 2, 93-98 (1975). 
[42] Podstrigach Ya. S., Burak Ya. I., Gachkevich A. R., Chernyavskaya L. V. Thermoelasticity of conductive bodies. Kiyev, Nauk. dumka (1977).

[43] Nyashin Yu. I. About the control of material processing in order to reduce residual tension. Applied mathematics and mechanics. 45, n.2, 371-375 (1981).

[44] Nyashin Yu. Y., Pozdeev A. A., Trusov P. V. Large elastoplastic deformation: theory, algorithms, applications. Moscow, Nauka (1986).

[45] Podstrigach Ya. S., Burak Ya. Y., Besedina L. P. Optimal heating of an irregular cylindrical shell. Phys.chemical mechanics of materials. 2, 67-74 (1971).

[46] Baranovsky V. I., Gusev V.N., Ivanov V. N. et al. Production of color kinescopes / Ed. V. I. Baranovsky. Moscow, Energia (1978).

[47] Podstrigach Ya. S., Kosarchin V. I., Margolin A. M., Chernuha Yu. A. Analysis of thermal tensions in the elements of electronic devices in the vicinity of metal inclusions. Mat. methods and phys.-mech. fields. 28, p.15 (1988).

[48] Butkovskiy A. G. Methods of control of systems with distributed parameters. Moscow, Nauka (1975).

[49] Mikhlin S. G. Numerical realization of variational methods. Moscow, Nauka (1966).

[50] Polak E. Numerical methods of optimization. Moscow, Mir (1974).

[51] Himmelblau D. Application of nonlinear programming. Moscow, Mir (1975).

[52] Chernousko F. M., Banichuk N. V. Variational problems in mechanics and control. Moscow, Nauka (1973).

[53] Grigorenko Ya. M., Budak V. D., Grigorenko O. Ya. Solving problems of theory of shells based on discrete-continuous methods. Nikolaev, Ilion (2010).

[54] Goodal I. W., Whituwan C. M. On optimizing thermal stresses in cylindrical shells. Intern. I. Mech. Shi. 15(1), 99-107 (1973).

[55] Gachkevich A.,Irza E., Kaspersky Z. Thermomechanical models of quantitative description of the mechanical behavior of glass bodies of rotation with the thermal load. Visnyk of Lviv National University. Ser. Mech.-math. 73, 37-44 (2010).

[56] Gachkevich A. R., Budz S. F., Irza E. M., Kaspersky Z. I. Optimization of stress-deformed state of the glass shells of rotation with a local high-temperature heating. Theoretical and applied mechanics. 40, 146-150 (2005).

[57] Ritz W. Ü line neue Methode zur Losung gewsser Variations - Probleme der Matematishen. Physik. H.1, s.135 (1908).

[58] Pontryagin P. S., Boltiansky V. G., Gamkrelidze R. V., Mishchenko E. F. The mathematical theory of optimal processes. Moscow, Fizmatgiz (1961).

[59] Yevtushenko Yu. G. Methods of solving extreme problems and their application in systems of optimization. Moscow, Nauka (1982).

[60] Burak Ya. I., Besedina L. P. Variable thickness local temperature fields for removal of residual intensity in the nonuniform cylindrical shells. Phys.-chemical. mechanics of materials. 2, $71-75$ (1973).

[61] Gachkevich N. G. Optimal for heavy duty heating glass piecewise-uniform shell of rotation consisting of elements of different geometric shapes. Mat. Methods and Phys.-Mech. Fields. 38, 142-147 (1995).

[62] Gachkevich O., Gachkevich M., Vorobets B., Trisch B., Gayevska L.: Methods of optimization of heating glass piecewise-uniform shells of revolving considering heat sensitivity of allowable intensity. Mashynoznavstvo. 12(126), 17-23 (2007). 


\title{
Математичні моделі і методи оптимізації режимів технологічного нагріву скляних кусково-однорідних оболонок. Стан досліджень
}

\author{
Гачкевич М. Г. ${ }^{1}$, Гачкевич О. Р. ${ }^{1,2}$, Торський А. Р. ${ }^{3}$, Дмитрук В. А. ${ }^{3,4}$ \\ ${ }^{1}$ Інститут прикладних проблем механіки $і$ математики ім. Я. С. Підстригача НАН України \\ вул. Наукова, 3-б, 79060, Лъвів, Україна \\ ${ }^{2}$ Політехніка Опольска \\ Прошковсъка вул., 76, 45-758 Ополе, Польща \\ ${ }^{3}$ Центр математичного моделювання Інституту прикладних проблем механіки $і$ математики \\ ім. Я. С. Підстригача НАН Украӥни \\ вул. Дудаєва, 15, 79005, Львів, Україна \\ ${ }^{4}$ Національний університет «Львівсъка політехніка» \\ вул. С. Бандери, 12, 79013, Львів, Украӥна
}

\begin{abstract}
Проаналізовано сучасний стан досліджень проблеми оптимізації відносно напруженого стану режимів технологічного нагріву кусково-однорідних скляних оболонкових елементів, важливої для розроблення різних раціональних виробничих процесів під час виготовлення пристроїв конкретного цільового призначення, зокрема, вакуумного і енергетичного обладнання. Окреслено напрями розвитку такого класу задач оптимізації та відповідні підходи до їх формулювання і розв'язування.
\end{abstract}

Ключові слова: теплові режими в виробничих прочесах, скляні кусково-однорідні оболонкові елементи, оптимізація відносно напруженого стану

2000 MSC: $74 \mathrm{~A} 10,74 \mathrm{~B} 10$

UDC: 539.3 